\title{
Don't Forget the Caregivers! A Discrete Choice Experiment Examining Caregiver Views of Integrated Youth Services
}

\author{
Lisa D. Hawke ${ }^{1}$ D $\cdot$ Lehana Thabane $^{2}$ (D) Leanne Wilkins $^{3} \cdot$ Steve Mathias $^{4} \mathbb{D} \cdot$ Srividya Iyer $^{5}$ (D) Joanna Henderson ${ }^{1}$ (D)
}

Accepted: 11 March 2021 / Published online: 15 April 2021

(c) The Author(s) 2021

\begin{abstract}
Background The design and implementation of community-based integrated youth service hubs (IYSHs) is burgeoning around the world. This collaborative model of care aims to address barriers in youth service access by designing services that meet the needs of youth and caregivers. However, heterogeneity across models requires a better understanding of the preferences for key service characteristics.

Method A discrete choice experiment was conducted among 274 caregivers of youth aged 14-29 years with mental health challenges. The experiment consisted of 12 attributes with four levels each, representing different service components; additional measures were collected, including demographics and burden assessments. Utility values were calculated, representing the degree of preference for a given level of an attribute. Latent class analysis was conducted to understand subgroups with different service preferences, identifying three latent classes with differing IYSH service preferences.

Results The largest class ( $n=173,63.1 \%$ ), entitled 'Comprehensive, Integrative Service Access', strongly valued practical aspects of service design, such as rapid access and support for a wide range of needs. The 'Service Process Features' class $(n=67,24.5 \%)$ expressed a relative prioritization of process features of service access, while the smaller 'Caregiver Involvement' ( $n=34,12.4 \%$ ) class most highly prioritized caregiver involvement in their youths' services. Similar demographic characteristics and caregiver burden were found across classes, although participants in the Caregiver Involvement latent class were supporting younger youth.

Discussion and Conclusions Caregivers have diverse youth service preferences and relative priorities that should be taken into account when designing services. System designers and service providers are encouraged to take caregivers' preferences and priorities into account, alongside youth priorities, whether designing service delivery models or an individual service plan for a youth.
\end{abstract}

Joanna Henderson

Joanna.Henderson@ camh.ca

1 Margaret and Wallace McCain Centre for Child, Youth and Family Mental Health, Centre for Addiction and Mental Health; University of Toronto, Toronto, ON, Canada

2 Health Research Methods, Evidence, and Impact, McMaster University, Hamilton, ON, Canada

3 Margaret and Wallace McCain Centre for Child, Youth and Family Mental Health, Centre for Addiction and Mental Health, Toronto, ON, Canada

4 Foundry, Vancouver, BC, Canada

5 McGill University; ACCESS Open Minds (Youth Mental Health Services Research Network), Montreal, QC, Canada

\section{Key Points for Decision Makers}

It is important to consider the perspectives of caregivers when designing and scaling integrated youth service hub models.

This study identified caregivers' priorities regarding the components of integrated youth service hub models.

Caregivers as a whole prefer rapid access to a diversity of youth services during evening and weekend hours, with e-health services available and caregiver involvement in care.

Subgroups of caregivers highly prioritize aspects of access to comprehensive integrative services, service process features, and caregiver involvement in youth care. 


\section{Background}

Across a wide range of mental health and substance use (MHSU) disorders, first onset most often occurs during adolescence and young adulthood [1]. Furthermore, youth mental health disorder prevalence rates are rising [2]. Despite the high prevalence, only a minority of youth with such concerns access treatment, and the treatments available are often neither timely nor evidence-based, with considerable negative repercussions [3-6]. Youth face complex pathways into care, often through suboptimal routes with multiple service contacts [7, 8]. Additionally, youth and families experience many barriers in accessing services, such as long wait times, uncoordinated services, lack of access to appropriate specialists, age-based transitions, and stigma [9-13]. Attention to family members is also of particular importance, since family members of youth with MHSU challenges often experience caregiver burden $[14,15]$.

Integrated youth service hubs (IYSHs) are an emerging model of care that provide holistic, youth-focused services $[16,17]$. They integrate MHSU services, physical health care, and other community and social services in a one-stopshop setting within the community. IYSH models are rapidly being developed and scaled around the world. Examples in Canada [18] include the Foundry model in British Columbia [19], Youth Wellness Hubs Ontario (YWHO) in Ontario [20], and the pan-Canadian Access Open Minds project [21]. International examples include headspace in Australia [22] and Jigsaw in Ireland [23], among others.

IYSH models explicitly aim to address service access barriers in youth MHSU care. IYSH models typically define 'youth' as adolescents and young adults, including transitional aged youth who face particular service access barriers [24]. The models work by bringing together evidence-based services for multiple areas of need in an integrated manner, all in one youth-friendly setting, with walk-in or other rapid access models [25, 26]. IYSHs address a wide variety of youth needs, spanning the continuum from evidence-based treatments for discrete disorders to important social services, supporting young people in all areas of their lives through a social determinants of health and bioecological framework [18]. They do so in part by bringing various partner agencies together to provide comprehensive sets of services and increasing service integration, which has been lacking in youth services [27]. The goal is to provide holistic, developmentally informed services across the developmental transition from childhood to adulthood. Examples of types of services included in these models are psychotherapy, psychiatry, primary care, peer support, care navigation, and housing support.

While IYSH models generally include specific evidencebased interventions, they also include other services and components packaged together in unique, integrative ways and settings that have less evidence behind them. Our scoping review [25] found many similarities across models in terms of key components and principles (e.g. rapid access, evidencebased services, service integration), which might be presumed to be universally important; however, we also found important inconsistencies across models (e.g. means of access, setting, range of service providers). Models are developed locally using collaborative teams, a service development approach, and available resources. They tend to include components thought to support youth in engaging with their services, such as an accessible location, the offer of evening and weekend hours, and the provision of 'youth-friendly' services and features [12] that are responsive to youth and family contexts. However, an evidence gap emerges regarding the components that are most critical and should be the highest priorities for model development and scale.

When designing patient-centred health services to meet the needs of service users, understanding the perspectives of that population is essential [28, 29]. It is not surprising that youth and caregivers want their preferences to be heard when developing treatment plans [30]. By hearing and accounting for their preferences at an earlier stage, such as at systems design, it is possible to create patient-centered care service pathways that are responsive to youth and family needs, i.e. services that fit with the preferences of service users [31]. For youth services in particular, understanding preferences of both youth and caregivers is essential because of the key role that caregivers play in facilitating service utilization [32-34]. Ensuring that the services match the preferences of both youth and caregivers has been found to increase youth service acceptability and use [31, 33]. Unfortunately, the perspectives of youth and caregivers are rarely integrated in service planning, development, and research; this leaves a gap in terms of optimizing service design through patientoriented research and care [35].

This study expands on the emerging literature on IYSH models of youth MHSU service delivery. We take an empirical approach to identifying the core characteristics and features that an IYSH model should contain. We look beyond evidence-based treatments, to include the other service components and characteristics incorporated to make such models responsive to service user needs. The complete programme of research examines the perspectives of caregivers, youth, and service providers regarding the most important service characteristics to include in an IYSH model. This paper presents the findings regarding caregiver perspectives.

\subsection{Research Questions}

This study aims to identify (1) the IYSH service characteristics most important to caregivers of youth with mental health and/or substance use challenges, and (2) whether different latent classes of caregivers have different youth service preferences, and, if so, what defines these classes. 


\section{Method}

\subsection{Discrete Conjoint Experiment}

The Discrete Conjoint Experiment (DCE) methodology asks respondents to select product or service preferences packaged together in complex hypothetical scenarios. Drawn from marketing research methodologies, DCEs identify the relative importance of different service preferences, as well as participant subgroups with different preference sets.

This study followed the guidelines of the International Society for Pharmacoeconomics and Outcomes Research taskforce's report on Good Research Practices for Conjoint Analysis [36]. Guided by our scoping review of IYSH services [25], the team collaboratively developed DCE attributes and levels. The literature review was used to identify components of IYSH settings (attributes), and team discussions were used to establish levels for each attribute. Iterative versions were refined through team meetings and informal surveys. Internal team surveys were developed using REDCap software [37], presenting draft attributes and levels; research team members scored their appropriateness and provided open-ended feedback to refine them. A consultation meeting was held with six caregivers to further refine the attributes and levels. During this caregiver consultation, the DCE process was described and the full set of attributes and levels was presented, as well as DCE choice set examples; attributes and levels were discussed and feedback was collected. From each of these steps, the feedback obtained was integrated in order to create the DCE survey used in the next step. This tentative DCE survey was then pilot tested among four caregivers in two Ontario locations (one large city and one rural area) for finalization. The process consisted of, first, a researcher describing the study and overall attribute and level concepts, then the caregivers completing the survey with research staff and voicing their questions, concerns, or comments. This pilot testing resulted in the refining of the instructions and practice exercise to better guide participants through the DCE survey, as well as adjustments to the demographic survey. For example, based on the pilot testing, the number of practice exercises was reduced from three to one, as the DCE process was clear to pilot participants and the practice exercises were considered redundant. As a whole, pilot participants understood the survey and no major changes were required at this stage.

In the final DCE, there were 12 attributes, each with four levels. A sample choice task is shown in Fig. 1, and all attributes and levels are shown in electronic supplementary Fig. 1. The attributes contained four levels each, representing (1) Core Health Services; (2) Other Services; (3) Peer Support; (4) Cultural Sensitivity; (5) E-Health
Services; (6) Location; (7) Information Sharing with Caregivers; (8) Caregiver Involvement; (9) Age Range Served; (10) Time of Appointments; (11) Wait Times; and (12) Youth and Caregiver Engagement. For the complete set of attributes and levels, see electronic supplementary Fig. 1. Some overlap can be observed in the levels within some attributes, such as in the types of services offered; however, these were designed to reflect the multicomponent service options offered within IYSH settings. Using a partial profile design to minimize participant burden given the large number of attributes and levels [38], DCE tasks consisted of three service options, each containing one level of three attributes. Participants selected the most preferred option for youth (aged 14-29 years) with MHSU challenges. A balanced DCE algorithm optimized orthogonality and attribute/level balance. Random attribute and level combinations ensured that each participant's survey version was unique. Sawtooth Software's SSI Web [39] was used to administer the survey, hosted on a secure server at the Centre for Addiction and Mental Health (CAMH), in Toronto, ON, Canada. Recruitment occurred over a 4-month period from late 2019 to early 2020. Based on simulation analyses, the target sample size was 350 [40]; however, data collection was terminated at $N=274$ due to research shutdowns associated with the coronavirus disease 2019 (COVID-19) pandemic. With 274 participants, the design strength was 258.1. Comparatively, with a target number of 350 participants, the design strength was 331.1 , for a d-efficiency ratio of 78.0.

\subsection{Participants and Procedure}

A total of 274 caregivers were recruited over 5 months. Caregivers, or family members, were defined as individuals selfidentifying as being the primary caregiver of a youth aged 14-29 years with MHSU challenges. Recruitment occurred by circulating a study flyer with a web link to Ontario youthserving MHSU organizations, with a request to forward the flyer on to prospective participants. Median response time was $23 \mathrm{~min}$. Caregiver participants were offered the optional entry into a random draw for gift cards if they chose to provide their contact information, which was not linked to the survey data. Research Ethics Board approval was obtained from CAMH.

\subsection{Measures}

In addition to the DCE choice tasks, we collected demographic information, for both the participant themselves and for an index youth for whom they were providing care. Caregivers also completed the Burden Assessment Scale (BAS) [41], a 19-item scale that measures the amount of 
Fig. 1 Sample choice task

\begin{tabular}{|c|c|c|c|}
\hline & \multicolumn{3}{|c|}{$\begin{array}{l}\text { Question 1. Thinking about services for youth (aged 14-29) with mental health and/or } \\
\text { substance use challenges, what do you think is the best option? }\end{array}$} \\
\hline & Option 1 & Option 2 & Option 3 \\
\hline Core Health Services & $\begin{array}{l}\text { Mental health and } \\
\text { substance use counseling, } \\
\text { and medication } \\
\text { management. }\end{array}$ & $\begin{array}{l}\text { Only mental health } \\
\text { counseling. }\end{array}$ & $\begin{array}{l}\text { Mental health and } \\
\text { substance misuse } \\
\text { counseling, medication } \\
\text { management, and } \\
\text { physical/sexual health. }\end{array}$ \\
\hline $\begin{array}{l}\text { Peer Support (youth with } \\
\text { experience with mental health } \\
\text { and/or substance use } \\
\text { challenges) }\end{array}$ & $\begin{array}{l}\text { Recreational activities led } \\
\text { by trained peer support } \\
\text { worker. }\end{array}$ & $\begin{array}{l}\text { Mental health groups run } \\
\text { solely by a trained peer } \\
\text { support worker. }\end{array}$ & $\begin{array}{l}\text { Can talk to a trained peer } \\
\text { support worker, upon } \\
\text { request. }\end{array}$ \\
\hline \multirow[t]{2}{*}{$\begin{array}{l}\text { Service Sensitivity to Culture } \\
\text { (i.e., LGBTQ, Black, } \\
\text { Indigenous, and People of } \\
\text { Colour, Religion, Spirituality) }\end{array}$} & $\begin{array}{l}\text { Culturally-based services } \\
\text { are available for cultures } \\
\text { common to the local area. }\end{array}$ & $\begin{array}{c}\text { Can ask for a service } \\
\text { provider with a certain } \\
\text { cultural background, when } \\
\text { available. }\end{array}$ & $\begin{array}{c}\text { Can ask for a service } \\
\text { provider with a certain } \\
\text { cultural background, when } \\
\text { available. }\end{array}$ \\
\hline & TM & TM & $\sim$ \\
\hline
\end{tabular}

burden experienced by caregivers supporting a loved-one with mental health challenges. The 19 items are answered on a 4-point scale, where higher scores indicate a higher level of caregiver burden. The BAS yields a Total Burden Score, as well as two subscales: Subjective Burden (9 items, current alpha $=0.85)$ and Objective Burden (10 items, current alpha $=0.91)$. Total and scale scores were calculated as mean scores. The BAS has demonstrated acceptable content and construct validity [41]. It has been validated among caregivers of adults, as well as caregivers of children and adolescents [41, 42]. In a validation study among Canadian caregivers of children and adolescents with mental health and behavioural challenges, total average burden scores were 49 out of a maximum of 76 [42], which equates to a mean score of 2.6 on a 4-point scale. All measures were completed in English.

\subsection{Data Analysis}

We described the sample using descriptive statistics. Utility estimates were then calculated for each participant's DCE responses, using the hierarchical Bayesian method with Sawtooth Software [39]. With standardized, zero-centered utilities, the average utility range of attribute levels is set to 100 [43], where higher utility values indicate that a level has a higher relative value relative to the other levels of that attribute. The relative importance of each attribute is indicated by its proportional utility as a function of the total utility of all attributes. The utility value is the distance between the largest and smallest estimate of a level within the attribute. Using latent class analyses in Sawtooth Software's Latent Class module [39], we identified classes of caregiver participants with similar service preferences, assigning each participant a probability of belonging to a given latent class. Five replications were calculated for each latent class solution, using different starting seeds. Convergence was assumed for log-likelihood decreases of 0.01 or less. Latent class solutions were compared using the Bayesian Information Criteria (BIC), Akaike Information Criteria (AIC), and Akaike's Bayesian Information Criterion (ABIC), in conjunction with class sizes and interpretability (see electronic supplementary Table 1 for fit indices). For the retained three-class model, a descriptive presentation of the attribute rankings is provided. Names for the latent classes were established through team discussions informed by (1) their relative importance scores, particularly those that were orthogonal or distinct in priority/ rank compared with other classes (Table 2), and (2) the level endorsements for each attribute, particularly those preferred levels that are orthogonal or seem distinct compared with other classes. The remaining analyses were conducted using SPSS version 25 [44]. The latent classes were compared based on demographic characteristics and BAS scores. We examined rankings of the importance scores for the levels comprising the attribute.

\section{Results}

\subsection{Demographic Characteristics}

Demographic characteristics are presented in Table 1. The univariate majority of participants were female, educated, employed full time, financially stable, urban, and Caucasian, with good to excellent physical and mental health; however, only 33 (12.0\%) participants met this full multivariate demographic profile, demonstrating some diversity and intersectionality in the sample. The mean age of youth rated by the caregiver sample was 20.72 years ( standard deviation $[\mathrm{SD}]=4.32$ ). Youth rated by caregivers comprised $41.4 \%$ boys/young men, $49.1 \%$ girls/young women, and $9.5 \%$ transgender or gender diverse. Only 
Table 1 Sociodemographic characteristics of caregiver participants and the index youth who they reported supporting $(n=274)$

\begin{tabular}{|c|c|c|}
\hline Sociodemographic characteristic & $\begin{array}{l}\text { Youth, as rated by caregivers } \\
n(\%)\end{array}$ & $\begin{array}{l}\text { Caregivers } \\
n(\%)\end{array}$ \\
\hline \multicolumn{3}{|l|}{ Gender } \\
\hline Man/boy & $113(41.4)$ & $21(7.8)$ \\
\hline Woman/girl & $134(49.1)$ & $245(91.4)$ \\
\hline Transgender or gender diverse & $26(9.5)$ & $2(0.7)$ \\
\hline \multicolumn{3}{|l|}{ Ethnicity } \\
\hline Asian & $12(4.4)$ & $15(5.5)$ \\
\hline Black & $3(1.1)$ & $3(1.1)$ \\
\hline Indigenous & $5(1.8)$ & $3(1.1)$ \\
\hline Caucasian & $213(78)$ & $232(85.0)$ \\
\hline Another ethnicity & $40(14.7)$ & $20(7.3)$ \\
\hline \multicolumn{3}{|l|}{ Socioeconomic status } \\
\hline Live comfortably & NA & $155(59.6)$ \\
\hline Meet needs, with a little left & NA & $61(23.5)$ \\
\hline Basic expenses met or less & NA & $44(16.9)$ \\
\hline \multicolumn{3}{|l|}{ Employment } \\
\hline Full-time & $27(10.4)$ & $149(57.8)$ \\
\hline Part-time & $63(24.3)$ & $26(10.1)$ \\
\hline Unemployed & $157(60.6)$ & $36(14.0)$ \\
\hline Other & $12(4.6)$ & $47(18.2)$ \\
\hline \multicolumn{3}{|l|}{ Education level } \\
\hline High school or less & $174(67.2)$ & $12(4.6)$ \\
\hline Some college/university & $55(21.2)$ & $39(15.0)$ \\
\hline Graduate college/university & $30(11.6)$ & $209(80.4)$ \\
\hline \multicolumn{3}{|l|}{ Region size } \\
\hline Rural/small (population 0-30,000) & NA & $40(14.8)$ \\
\hline Medium (population 30,001-99,999) & NA & $49(18.1)$ \\
\hline Large (population over 100,000) & NA & $182(67.2)$ \\
\hline \multicolumn{3}{|l|}{ Born in Canada } \\
\hline Yes & $241(93.1)$ & $216(84.4)$ \\
\hline \multicolumn{3}{|l|}{ First language } \\
\hline English & $250(96.5)$ & $233(90.7)$ \\
\hline \multicolumn{3}{|l|}{ Physical health } \\
\hline Good/very good/excellent & $162(62.5)$ & $226(86.9)$ \\
\hline Fair/poor & $97(37.5)$ & $34(13.1)$ \\
\hline \multicolumn{3}{|l|}{ Mental health } \\
\hline Good/very good/excellent & $33(12.7)$ & $191(73.5)$ \\
\hline Fair/poor & $227(87.3)$ & $69(26.5)$ \\
\hline
\end{tabular}

$12.7 \%$ of caregivers rated their youth's mental health as 'good' or better.

\subsection{Overall Preferences Irrespective of Class}

Observing preferences within each attribute irrespective of latent class or relative importance between attributes, caregiver latent classes universally indicated that models without caregiver involvement or information sharing with caregivers would not be desirable. Caregivers also preferred that rapid access be provided, including evening and weekend hours, in a specialized mental health setting. Caregivers endorsed that some level of e-health services be integrated in conjunction with in-person services. Overall, they preferred settings offering a diversity of services across core services and additional social service supports; legal support services were not a priority. They collectively negatively endorsed situating services in a school setting. Levels within other attributes were mixed across classes. 


\subsection{Latent Class Analysis}

Electronic supplementary Table 1 presents latent class fit indices for models ranging from one to five classes. Considering model fit, class size, and interpretability, we retained the three-class model. DCE attribute rankings and importance scores are presented in Table 2. The importance scores indicate the proportion of the total importance represented by each attribute for each latent class (see the detailed results in electronic supplementary Fig. 1 regarding the level values within each attribute).

\subsubsection{Comprehensive, Integrative Service Access}

Latent class 1 represented the majority of the sample $(N=173,63.1 \%)$. This class most highly prioritized the attributes E-Health Services, Wait Times, Information Sharing, and Other Services. This latent class was distinct for their preference for access to comprehensive, integrative services. The least prioritized attributes were youth and family engagement in services, the time of appointments, and the age range served.

Caregivers belonging to this class prioritized a model in which e-health services provide a 24/7 supplement to in-person care. They also wanted the ability to schedule appointments via email, text, or online, and endorsed that services should be accessible either immediately or after about $72 \mathrm{~h}$. In the Other Services attribute, members of this latent class prioritized that a choice of service options be available to support youth in areas of education, employment, housing, income support, and legal issues. For the Information
Sharing attribute, caregivers in this latent class endorsed that youth and service providers should work together to decide which information to share with caregivers. There was some endorsement of a model in which information is available to caregivers with youth consent and in which service providers decide which information to share, but caregivers in this latent class were opposed to a model in which there was no information sharing with caregivers.

\subsubsection{Service Process Features}

The second latent class, comprising 67 participants (24.5\%), was labelled Service Process Features. This latent class prioritized a family-based, holistic approach to care, favouring service characteristics that might be considered 'youth friendly'. Specifically, they most strongly prioritized the following attributes: Information Sharing, Age Range, Caregiver Involvement, and Time of Appointments. The attributes with the least relative priority levels were Cultural Sensitivity, Engagement, and Core Health Services.

Members of the Service Process Features latent class prioritized either service providers deciding which information to share with caregivers, or youth and service providers working together to make this decision. They had a strong negative utility value for a service model in which there was no information sharing with caregivers. This latent class endorsed that services be delivered to an age range of 12-29 years, with services for those aged over 29 years also available. Participants were less likely to endorse more restrictive age ranges and service settings open to younger children, but endorsed flexible hours-either $24 / 7$ or with
Table 2 Caregiver attribute importance scores and rankings for components of integrated youth service hubs for each of the three latent classes of participants

\begin{tabular}{|c|c|c|c|c|c|c|}
\hline & \multicolumn{2}{|c|}{$\begin{array}{l}\text { Comprehensive, integra- } \\
\text { tive service access }[n= \\
173]\end{array}$} & \multicolumn{2}{|c|}{$\begin{array}{l}\text { Service process features } \\
{[n=67]}\end{array}$} & \multicolumn{2}{|c|}{$\begin{array}{l}\text { Caregiver involve- } \\
\text { ment }[n=34]\end{array}$} \\
\hline & $I$ & $R$ & $I$ & $R$ & $I$ & $R$ \\
\hline Core health services & 7.74 & 8 & 4.86 & 10 & 5.43 & 10 \\
\hline Other services & 10.10 & 4 & 8.35 & 7 & 3.66 & 12 \\
\hline Caregiver involvement & 9.30 & 5 & 11.47 & 3 & 14.72 & 2 \\
\hline Peer support & 7.42 & 9 & 5.84 & 8 & 5.82 & 8 \\
\hline Cultural sensitivity & 7.65 & 6 & 2.40 & 12 & 4.13 & 11 \\
\hline E-health services & 12.81 & 1 & 5.46 & 9 & 5.80 & 9 \\
\hline Age range & 6.96 & 10 & 12.04 & 2 & 6.29 & 7 \\
\hline Time of appointments & 5.07 & 11 & 10.84 & 4 & 7.93 & 6 \\
\hline Wait times & 11.34 & 2 & 10.05 & 6 & 8.85 & 5 \\
\hline Location & 8.73 & 7 & 10.79 & 5 & 11.47 & 3 \\
\hline Engagement & 1.89 & 12 & 2.53 & 11 & 11.03 & 4 \\
\hline Information sharing & 10.99 & 3 & 15.38 & 1 & 14.86 & 1 \\
\hline
\end{tabular}

$R$ Rank of each attribute's importance score within informant and segment. $I$ Importance score of each attribute. Relative importance scores represent a percentage of value assigned to each attribute relative to the other attributes 
evening and weekend hours. They also prioritized the option of being involved in family counselling with youth or being involved in counselling decisions with youth, and were less likely to choose a service delivery model in which caregivers received their own counselling or in which there was no caregiver involvement.

\subsubsection{Caregiver Involvement}

The third latent class accounted for 34 caregivers, or $12.4 \%$ of the sample. This smaller proportion of participants most strongly prioritized a high level of involvement in the care of their youth, irrespective of the types of services offered, leading to this class being called Caregiver Involvement. The attributes most strongly endorsed in this latent class were Information Sharing, Caregiver Involvement, Location, and Engagement, while the attributes with the least relative priority were Other Services, Cultural Sensitivity, and Core Health Services.

For the Information Sharing attribute, participants in the Caregiver Involvement latent class prioritized caregivers having access to youth personal information (with youth consent as per the level provided) or preferred that youth and service providers work together to decide which information to share. There was a large negative utility value for no information sharing with caregivers. They also strongly endorsed that caregivers should be involved in decisions regarding youth counselling or that caregivers should be involved in family counselling with youth. Little value was placed on caregivers receiving their own separate services or counselling, and there was a strong negative reaction to the prospect of no caregiver involvement. Participants preferred that youth and caregivers play a leadership role in making decisions for the organization, or that they should be on an advisory group. This latent class also prioritized housing the services in a youth café and recreation centre or an office that specializes in mental health services, as opposed to a hospital, doctor's office, or school environment.

\subsection{Participant Characteristics by Latent Class}

None of the demographic characteristics of caregivers were significantly different across classes (Table 3 ). Youth rated by caregivers were also similar across latent classes in gender, physical health, and mental health; however, caregivers in the Caregiver Involvement class were reporting on younger youth compared with those in the other two classes.

Total levels of the BAS did not differ among latent classes $(F(2,254)=1.087, p=0.34)$. All latent classes reported similar total burden scores (Comprehensive, Integrative Service Access: $M=3.07, S D=0.60$; Service Process Features: $M=2.94, S D=0.70$; Caregiver Involvement: $M=3.10, S D=0.63$ ). Similarly, no significant differences were found in the objective burden subscale $(F$ $(2,254)=1.020, p=0.36)$. All classes featured similar levels of this subscale (Comprehensive, Integrative Service Access: $M=3.14, S D=0.65$; Service Process Features: $M=3.00, S D=0.75$; Caregiver Involvement: $M=3.14$, $S D=0.65)$. Subjective burden was also not significantly different $(F(2,254)=0.829, p=0.44)$ across latent classes (Comprehensive, Integrative Service Access: $M=2.99$, $S D=0.66$; Service Process Features: $M=2.88, S D=0.81$; Caregiver Involvement: $M=3.05, S D=0.67$ ).

\section{Discussion}

This study examined caregivers' perspectives on the service characteristics most important for IYSH settings. As a whole, caregivers preferred a diversity of services, with rapid access, e-health services, and caregiver involvement, in a specialized mental health setting. Three latent classes of caregivers emerged. When making trade-offs between service components, the first class most strongly prioritized practical aspects of access to comprehensive services; the second latent class most strongly prioritized service process features; and a third, small latent class most highly prioritized caregiver involvement in diverse aspects of the youth's care. Despite somewhat high levels of caregiver burden in the sample as a whole compared with previous research [42], the latent classes were similar in terms of burden and demographic characteristics.

A recent small qualitative study from The Netherlands examined caregiver preferences in integrated service contexts [45]. That study found several themes that reflect the current study's quantitative findings: families wanted rapid access to family-centered, holistic, collaborative services, with smooth transitions, strong privacy policies, and parental involvement in decision making. These findings largely overlap with the current study and provide confirmation of those findings from a quantitative perspective, with international generalization. This study adds to those findings by demonstrating the existence of different constellations of preferences across caregivers, with some of these preferences being of different relevant importance than others.

In the current study, caregivers' prioritization of rapid access to services, when making trade-offs among various service features, comes as no surprise given the long wait times in the field [6] and the broad literature indicating wait times as a barrier [11, 45-48]. This finding supports the ongoing development of IYSH models with walk-in or other rapid access models as a key priority as the models are scaled. However, some caregivers did not highly prioritize the diversity of core or supplementary services; some caregivers appear to want access to services that they can be involved in, irrespective of what those services might be. 
Table 3 Sociodemographic characteristics of participants across the three latent class

\begin{tabular}{|c|c|c|c|c|c|}
\hline Caregiver characteristics & $\begin{array}{l}\text { Comprehensive, inte- } \\
\text { grative service access } \\
n=173 \\
n(\%)\end{array}$ & $\begin{array}{l}\text { Service process } \\
\text { features } \\
n=67 \\
n(\%)\end{array}$ & $\begin{array}{l}\text { Caregiver involve- } \\
\text { ment } \\
n=34 \\
n(\%)\end{array}$ & $P$ value & $\varphi$ \\
\hline \multicolumn{6}{|l|}{ Gender $^{\mathrm{a}}$} \\
\hline Man & $9(5.4)$ & $8(12.1)$ & $4(12.1)$ & 0.144 & 0.12 \\
\hline Woman & $158(94.6)$ & $58(87.9)$ & $29(87.9)$ & & \\
\hline \multicolumn{6}{|l|}{ Ethnicity } \\
\hline White & $149(86.1)$ & $54(81.8)$ & $29(85.3)$ & 0.705 & 0.05 \\
\hline Non-White & $24(13.9)$ & $12(18.2)$ & $5(14.7)$ & & \\
\hline \multicolumn{6}{|l|}{ Socioeconomic status } \\
\hline Lives comfortably & $102(62.2)$ & $35(54.7)$ & $18(56.3)$ & 0.535 & 0.07 \\
\hline Lives less than comfortably & $62(37.8)$ & $29(45.3)$ & $14(43.8)$ & & \\
\hline \multicolumn{6}{|l|}{ Employment } \\
\hline Employed & $136(83.4)$ & $49(76.6)$ & $24(77.4)$ & 0.426 & 0.08 \\
\hline Unemployed/other & $27(16.6)$ & $15(23.4)$ & $7(22.6)$ & & \\
\hline \multicolumn{6}{|l|}{ Region size } \\
\hline Rural/small urban & $52(30.6)$ & $27(40.3)$ & $10(29.4)$ & 0.323 & 0.09 \\
\hline Large urban & $118(69.4)$ & $40(59.7)$ & $24(70.6)$ & & \\
\hline \multicolumn{6}{|l|}{ First language } \\
\hline English & $147(91.3)$ & $56(87.5)$ & $30(93.8)$ & 550 & 0.07 \\
\hline \multicolumn{6}{|l|}{ Born in Canada } \\
\hline Yes & $125(83.3)$ & $52(83.9)$ & $29(90.6)$ & 0.579 & 0.07 \\
\hline \multicolumn{6}{|l|}{ Education level } \\
\hline High school/some post-secondary & $30(18.3)$ & $16(25.0)$ & $5(15.6)$ & 0.431 & 0.08 \\
\hline Graduated post-secondary & $134(81.7)$ & $48(75.0)$ & $27(84.4)$ & & \\
\hline \multicolumn{6}{|l|}{ Physical health } \\
\hline Good or better & $147(89.6)$ & $55(85.9)$ & $24(75.0)$ & 0.077 & 0.14 \\
\hline Fair or worse & $17(10.4)$ & $9(14.1)$ & $8(25.0)$ & & \\
\hline \multicolumn{6}{|l|}{ Mental health } \\
\hline Good or better & $123(75.0)$ & $44(68.8)$ & $24(75.0)$ & 0.617 & 0.06 \\
\hline Fair or worse & $41(25.0)$ & $20(31.3)$ & $8(25.0)$ & & \\
\hline \multicolumn{6}{|l|}{ Youth characteristics } \\
\hline \multicolumn{6}{|l|}{ Age, years } \\
\hline$<18$ & $48(28.6)$ & $15(22.7)$ & $16(48.5)^{*}$ & 0.013 & 0.22 \\
\hline $18-24$ & $86(51.2)$ & $30(45.5)$ & $15(45.5)$ & & \\
\hline $25-29$ & $34(20.2)$ & $21(31.8)$ & $2(6.1)^{*}$ & & \\
\hline \multicolumn{6}{|l|}{ Gender $^{\mathrm{a}}$} \\
\hline Man/boy & $66(38.2)$ & $32(48.5)$ & $15(44.1)$ & 0.575 & 0.07 \\
\hline Woman/girl & $88(50.9)$ & $29(43.9)$ & $17(50.0)$ & & \\
\hline Transgender/gender diverse & $19(11.0)$ & $2(5.9)$ & $5(7.6)$ & & \\
\hline \multicolumn{6}{|l|}{ Ethnicity } \\
\hline Caucasian & $135(78.0)$ & $53(80.3)$ & $25(73.5)$ & 0.741 & 0.05 \\
\hline Another ethnicity & $38(22.0)$ & $13(19.7)$ & $9(26.5)$ & & \\
\hline \multicolumn{6}{|l|}{ Employment } \\
\hline Employed & $61(37.4)$ & $25(39.1)$ & $10(31.3)$ & 0.747 & 0.05 \\
\hline Unemployed/other & $102(62.6)$ & $39(60.9)$ & $22(68.8)$ & & \\
\hline \multicolumn{6}{|l|}{ Education level } \\
\hline High school or less & $114(69.9)$ & $38(59.4)$ & $22(68.8)$ & 0.638 & 0.10 \\
\hline Some college/university & $30(18.4)$ & $17(26.6)$ & $6(18.8)$ & & \\
\hline
\end{tabular}


Table 3 (continued)

\begin{tabular}{|c|c|c|c|c|c|}
\hline Caregiver characteristics & $\begin{array}{l}\text { Comprehensive, inte- } \\
\text { grative service access } \\
n=173 \\
n(\%)\end{array}$ & $\begin{array}{l}\text { Service process } \\
\text { features } \\
n=67 \\
n(\%)\end{array}$ & $\begin{array}{l}\text { Caregiver involve- } \\
\text { ment } \\
n=34 \\
n(\%)\end{array}$ & $P$ value & $\varphi$ \\
\hline Graduate college/university & $19(11.7)$ & $9(14.1)$ & $4(12.5)$ & & \\
\hline \multicolumn{6}{|l|}{ Physical health } \\
\hline Good/very good/excellent & $96(58.9)$ & $42(65.6)$ & $24(75.0)$ & 0.192 & 0.11 \\
\hline Fair/poor & $67(41.1)$ & $22(34.4)$ & $8(25.0)$ & & \\
\hline \multicolumn{6}{|l|}{ Mental health } \\
\hline Good/very good/excellent & $17(10.4)$ & $9(14.1)$ & $7(21.9)$ & 0.188 & 0.11 \\
\hline Fair/poor & $147(89.6)$ & $55(85.9)$ & $25(78.1)$ & & \\
\hline
\end{tabular}

$* p<0.05$

${ }^{a}$ Transgender and gender diverse genders were not analysed due to small cell sizes

Caregiver involvement in the treatment process emerged as a strong priority, at different levels for different participant groups. Previous work has shown that caregivers often feel excluded from their youth's or young adult's care, which they consider a considerable barrier and driver of dissatisfaction [7, 11, 13, 47, 49]. Caregiver involvement can be a facilitator of treatment retention for young people [48]. Whether through family-focused treatment with the youth and caregiver together or through interventions aimed at the parent themselves, youth and caregivers can benefit from involvement from a whole-family approach [48-50]. In terms of information sharing, caregivers expressed wanting opportunities to communicate with service providers about their youths' care and to understand their care $[7,13]$. Somewhat paradoxically, but importantly, youth have expressed that confidentiality is a premise of youth-friendly services $[12,51]$. Since strong caregiver involvement is a leading priority for a small proportion of caregivers, and a moderate priority for others, this is an important area of ongoing negotiation between the youth, service provider, and interested caregivers, as the youths' service needs evolve.

Many caregivers also prefer aspects of services considered to be 'youth friendly' [12]. For example, rapid access and the use of technology to book appointments, locating services in a youth-accessible setting, providing holistic services, reducing age-based transitions, and offering convenient hours are all preferred components [11-13]. Providing services and settings that reduce or facilitate age-based transitions is a particular priority of some caregivers [7]. By making services responsive to youth needs and preferences, it is hypothesized that service access and retention will increase, improving outcomes [12]. Caregivers appear to recognize this, and many are ready and willing to express their preferences to help shape services. However, the attributes and levels were designed to capture caregivers' perspectives on the service components most important for their youth; results may have been different if the study specifically queried caregivers on service components most important to caregivers themselves.

These findings provide valuable insights to support the design of IYSH settings that correspond with the preferences of caregivers. Caregivers are an important stakeholder in youth services, given their close involvement with the youth [52]. For some youth, caregiver support for service access, and service designs that are appealing to caregivers, increase the likelihood that the youth will use services $[11,33]$. Taking caregiver preferences into account in the design and scale of IYSH models is important to ensuring an appealing and accessible model of care.

Most importantly, service developers are encouraged to engage youth and caregivers in the design and development of youth-oriented services. Engagement is a core component of IYSH development and is considered key to developing services that are responsive to youth and family needs [25]. While not all caregivers prioritize engagement as a key design preference, some are ready and willing to engage with organizations, at both the decision-making and service levels, to help optimize services for a broad range of families seeking services [53]. Caregivers should be engaged, alongside youth, in the development of both the service pathways and evaluations of service impact, as their important voices can help improve both the services and evaluation projects.

In sum, to meet the needs of the caregivers supporting young people, IYSH service developers are encouraged to continue to prioritize rapid access to a diversity of services in accessible environments, in line with their current orientation. They are also encouraged to expand the incorporation of technology into services, an area of work that is not yet fully optimized at a broad scale. Another area for further policy and procedural development within IYSH settings is information sharing with caregivers; IYSHs are encouraged 
to establish clear opportunities and guidelines for the involvement of those caregivers who wish to be involved in their youth's services, with flexibility to meet the diverse needs of all those involved. There must also be a structure in place to guide conversations with the youth about caregiver involvement in order to come to person-level decisions that best meet everyone's needs.

\subsection{Limitations}

While the online survey was open to any caregivers of youth with mental health or substance use challenges across Ontario, it did not specifically utilize a strategy to recruit a sample representative of the population of Ontario caregivers, and the results may therefore not be generalizable; however, consistency with previous research suggests some level of generalizability. Despite substantial intersectionality in demographic profiles, a larger, more diverse sample would provide more information about the preferences of different subgroups. Caregivers without internet access would not have been reached by the current study. It is important to note that these findings represent the service priorities of predominantly educated and financially stable, Canadian-born, Caucasian female caregivers with internet access. Future research should examine the preferences of other population subgroups from an equity and diversity standpoint.

In addition, the strengths of the relative preferences is dependent on the service characteristics that comprised the DCE attributes and levels. While a substantial development process took place, it is possible that some priorities were missed, and overlap between attributes and levels may have influenced the findings. For example, the levels representing the types of core health services progressively built on each other, which may have affected the ability to detect specific preferences for one specific service component. In addition, priorities for service characteristics may change sustainability due to the effects of the COVID-19 pandemic, which is currently having major impacts on service design models and exposing youth and caregivers to new service models.

\section{Conclusions}

Understanding caregiver preferences is important in designing services that youth will access and benefit from. While caregivers have a diversity of preferences, considering the role of the caregiver in the services is an important aspect of these services. Providing easy-to-access services that address a range of youth needs and acknowledge the role of caregivers in the youth's care is important. System designers and service providers are encouraged to take caregivers' relative priorities into account, alongside youth priorities, when designing service delivery models and when developing service plans for an individual youth.

Supplementary Information The online version contains supplementary material available at https://doi.org/10.1007/s40271-021-00510-6.

\section{Declarations}

Funding This study was funded by the Canadian Institutes of Health Research (CIHR).

Conflict of Interest Lisa D. Hawke, Lehana Thabane, Leanne Wilkins, Steve Mathias, Srividya Iyer, and Joanna Henderson have no conflicts of interest to declare.

Availability of Data and Material Data are available upon reasonable request and with Research Ethics Board approval.

Consent to Participate Electronic informed consent was obtained from all participants.

Code Availability Not applicable.

Ethics Ethics approval was obtained from the Research Ethics Board of $\mathrm{CAMH}$.

Informed consent Informed consent was obtained from all participants.

Acknowledgements The authors would like to thank the Youth Engagement Facilitators at CAMH for their support on this study. They also thank all members of the broader research team for their support, as well as the participants for taking the time to participate in this study.

Author Contributions LH contributed to the design and conduct of the study, analysis of the data, interpretation of the findings, and drafted the manuscript. LT contributed to the design of the study and the analysis and interpretation of the data and edited and approved the manuscript. LW contributed to the design and conduct of the study and edited and approved the manuscript. SI contributed to the design of the study and edited and approved the manuscript. SM contributed to the design of the study and edited and approved the manuscript. JH contributed to the design and conduct of the study, interpretation of the findings, and edited and approved the manuscript.

Open Access This article is licensed under a Creative Commons Attribution-NonCommercial 4.0 International License, which permits any non-commercial use, sharing, adaptation, distribution and reproduction in any medium or format, as long as you give appropriate credit to the original author(s) and the source, provide a link to the Creative Commons licence, and indicate if changes were made. The images or other third party material in this article are included in the article's Creative Commons licence, unless indicated otherwise in a credit line to the material. If material is not included in the article's Creative Commons licence and your intended use is not permitted by statutory regulation or exceeds the permitted use, you will need to obtain permission directly from the copyright holder. To view a copy of this licence, visit http://creativecommons.org/licenses/by-nc/4.0/. 


\section{References}

1. Kessler RC, Amminger GP, Aguilar-Gaxiola S, Alonso J, Lee S, Ustun TB. Age of onset of mental disorders: a review of recent literature. Curr Opin Psychiatry. 2007;20(4):359-64. https://doi. org/10.1097/YCO.0b013e32816ebc8c.

2. Wiens K, Bhattarai A, Pedram P, Dores A, Williams J, Bulloch A, et al. A growing need for youth mental health services in Canada: examining trends in youth mental health from 2011 to 2018. Epidemiol Psychiatr Sci. 2020;29:e115. https://doi.org/10.1017/ S2045796020000281.

3. Ratnasingham S, Cairney J, Manson H, Rehm J, Lin E, Kurdyak P. The burden of mental illness and addiction in Ontario. Can J Psychiatr. 2013;58(9):529-37.

4. Boyle MH, Georgiades K. Disorders of Childhood and Adolescence. In: Cairney J, Streiner D, editors. Mental disorders in Canada: An epidemiological perspective. Toronto: University of Toronto Press; 2009.

5. Reid GJ, Brown JB. Money, case complexity, and wait lists: perspectives on problems and solutions at children's mental health centers in Ontario. J Behav Health Serv Res. 2008;35(3):334-46.

6. Kowalewski K, McLennan JD, McGrath PJ. A preliminary investigation of wait times for child and adolescent mental health services in Canada. J Can Acad Child Adolesc Psychiatry. 2011;20(2):112-9.

7. Hovish K, Weaver T, Islam Z, Paul M, Singh SP. Transition experiences of mental health service users, parents, and professionals in the United Kingdom: a qualitative study. Psychiatr Rehabil J. 2012;35(3):251-7. https://doi.org/10.2975/35.3.2012.251.257.

8. MacDonald K, Fainman-Adelman N, Anderson KK, Iyer SN. Pathways to mental health services for young people: a systematic review. Soc Psychiatry Psychiatr Epidemiol. 2018;53(10):100538. https://doi.org/10.1007/s00127-018-1578-y.

9. Moroz N, Moroz I, Slovinec DM. Mental health services in Canada: barriers and cost-effective solutions to increase access. Healthc Manag Forum. 2020;33(6):282-7. https://doi.org/10. 1177/0840470420933911.

10. Brown A, Rice SM, Rickwood DJ, Parker AG. Systematic review of barriers and facilitators to accessing and engaging with mental health care among at-risk young people. Asia Pac Psychiatry. 2016;8(1):3-22. https://doi.org/10.1111/appy.12199.

11. Reardon T, Harvey K, Baranowska M, O'Brien D, Smith L, Creswell C. What do parents perceive are the barriers and facilitators to accessing psychological treatment for mental health problems in children and adolescents? A systematic review of qualitative and quantitative studies. Eur Child Adolesc Psychiatry. 2017;26(6):623-47. https://doi.org/10.1007/ s00787-016-0930-6.

12. Hawke LD, Mehra K, Settipani C, Relihan J, Darnay K, Chaim G, et al. What makes mental health and substance use services youth friendly? A scoping review of literature. BMC Health Serv Res. 2019;19(1):257. https://doi.org/10.1186/s12913-019-4066-5.

13. Paul M, Street C, Wheeler N, Singh SP. Transition to adult services for young people with mental health needs: a systematic review. Clin Child Psychol Psychiatry. 2015;20(3):436-57. https:// doi.org/10.1177/1359104514526603.

14. Shah AJ, Wadoo O, Latoo J. Psychological distress in carers of people with mental disorders. Br J Med Pract. 2010;33(3):a327.

15. Rodriguez-Meirinhos A, Antolin-Suarez L, Oliva A. Support needs of families of adolescents with mental illness: a systematic mixed studies review. Arch Psychiatr Nurs. 2018;32(1):152-63. https://doi.org/10.1016/j.apnu.2017.09.004.

16. Malla A, Iyer S, McGorry PD, Cannon M, Coughlan H, Singh $\mathrm{S}$, et al. From early intervention in psychosis to youth mental health reform: a review of the evolution and transformation of mental health services for young people. Soc Psychiatry Psychiatr Epidemiol. 2016;51(3):319-26. https://doi.org/10.1007/ s00127-015-1165-4.

17. McGorry PD, Bates T, Birchwood M. Designing youth mental health services for the 21st century: examples from Australia, Ireland and the UK. Br J Psychiatry Suppl. 2013;54:s30-5. https:// doi.org/10.1192/bjp.bp.112.119214.

18. Halsall T, Manion I, Iyer SN, Mathias S, Purcell R, Henderson J. Trends in mental health system transformation: integrating youth services within the Canadian context. Healthc Manage Forum. 2019;32(2):51-5. https://doi.org/10.1177/0840470418808815.

19. BC-IYSI Working Group. British Columbia Integrated Youth Services Initiative: Rationale and Overview. Victoria: BC-IYSI Working Group; 2015.

20. Youth Wellness Hubs Ontario. Youth Wellness Hubs Ontario. 2020. www.youthhubs.ca. Accessed 16 Sept 2020.

21. Malla A, Iyer S, McGorry P, Cannon M, Coughlan H, Singh $S$, et al. From early intervention in psychosis to youth mental health reform: a review of the evolution and transformation of mental health services for young people. Soc Psychiatry Psychiatr Epidemiol. 2016;51(3):319-26. https://doi.org/10.1007/ s00127-015-1165-4.

22. McGorry PD, Tanti C, Stokes R, Hickie IB, Carnell K, Littlefield LK, et al. headspace: Australia's National Youth Mental Health Foundation-where young minds come first. Med J Aust. 2007;187(7 Suppl):S68-70.

23. Illback RJ, Bates T, Hodges C, Galligan K, Smith P, Sanders $\mathrm{D}$, et al. Jigsaw: engaging communities in the development and implementation of youth mental health services and supports in the Republic of Ireland. J Ment Health. 2010;19(5):422-35. https://doi.org/10.3109/09638231003728141.

24. Mandarino K. Transitional-age youths: barriers to accessing adult mental health services and the changing definition of adolescence. J Hum Behav Soc Environ. 2014;24(4):462-74. https://doi.org/10. 1080/10911359.2013.835760.

25. Settipani CA, Hawke LD, Cleverley K, Chaim G, Cheung A, Mehra K, et al. Key attributes of integrated communitybased youth service hubs for mental health: a scoping review. Int J Ment Heal Syst. 2019;13:52. https://doi.org/10.1186/ s13033-019-0306-7.

26. Hetrick SE, Bailey AP, Smith KE, Malla A, Mathias S, Singh SP, et al. Integrated (one-stop shop) youth health care: best available evidence and future directions. Med J Aust. 2017;207(10):S5-18. https://doi.org/10.5694/mja17.00694.

27. McGihon R, Hawke LD, Chaim G, Henderson J. Cross-sectoral integration in youth-focused health and social services in Canada: a social network analysis. BMC Health Serv Res. 2018;18(1):901. https://doi.org/10.1186/s12913-018-3742-1.

28. Brownlie EB, Chaim G, Heffernan O, Herzog T, Henderson J. Youth services system review: moving from knowledge cathering to implementation through collaboration, youth engagement, and exploring local community needs. Can J Commun Ment Health. 2017;36(2):133-49. https://doi.org/10.7870/cjcmh-2017-018.

29. Harkness J. Patient involvement: a vital principle for patientcentred health care. World Hosp Health Serv. 2005;41(2):12-6 $(\mathbf{4 0 - 3}))$.

30. Coates D. Client and parent feedback on a Youth Mental Health Service: the importance of family inclusive practice and working with client preferences. Int J Ment Health Nurs. 2016;25(6):52635. https://doi.org/10.1111/inm.12240.

31. Bombard Y, Baker GR, Orlando E, Fancott C, Bhatia P, Casalino $\mathrm{S}$, et al. Engaging patients to improve quality of care: a systematic review. Impl Sci. 2018;13(1):98. https://doi.org/10.1186/ s13012-018-0784-z.

32. Logan DE, King CA. Parental facilitation of adolescent mental health service utilization: a conceptual and empirical review. Clin 
Psychol Sci Pract. 2001;8(3):319-33. https://doi.org/10.1093/ clipsy.8.3.319.

33. Bannon WM, McKay MM. Are barriers to service and parental preference match for service related to urban child mental health service use? Fam Soc. 2005;86(1):30-4. https://doi.org/10.1606/ 1044-3894.1874.

34. Markoulakis R, Chan S, Levitt A. The needs and service preferences of caregivers of youth with mental health and/or addictions concerns. BMC Psychiatry. 2020;20(1):409. https://doi.org/10. 1186/s12888-020-02801-y.

35. Viswanathan M, Ammerman A, Eng E, Gartlehner G, Lohr KN, Griffith D, et al. Community-based participatory research: assessing the evidence. Rockville: Agency for Healthcare Research and Quality; 2004.

36. Bridges JF, Hauber AB, Marshall D, Lloyd A, Prosser LA, Regier DA, et al. Conjoint analysis applications in health-a checklist: a report of the ISPOR good research practices for conjoint analysis task force. Value Health. 2011;14(4):403-13. https://doi.org/10. 1016/j.jval.2010.11.013.

37. Harris PA, Taylor R, Minor BL, Elliott V, Fernandez M, O'Neal $\mathrm{L}$, et al. The REDCap consortium: building an international community of software platform partners. J Biomed Inform. 2019;95:103208. https://doi.org/10.1016/j.jbi.2019.103208.

38. Chrzan K. Using partial profile choice experiments to handle large numbers of attributes. Int J Mark Res. 2010;52(6):827-40. https:// doi.org/10.2501/S1470785310201673.

39. Sawtooth Software. Sawtooth Software, Version 9.8. Provo, UT: Sawtooth Software; 2019

40. Orme B. Sample size issues for conjoint analysis studies. Sawthooth Software Research paper Series. Sequim, WA: Sawthooth Software Inc.; 1998.

41. Reinhard SC, Gubman GD, Horwitz AV, Minsky S. Burden assessment scale for families of the seriously mentally ill. Eval Program Plann. 1994;17(3):261-9.

42. Murdoch DD, Rahman A, Barsky V, Maunula S, Cawthorpe D. The use of the burden assessment scale with families of a pediatric population. Community Ment Health J. 2014;50(6):703-10. https://doi.org/10.1007/s10597-014-9724-9.

43. Orme BK. Getting started with conjoint analysis: strategies for product design and pricing research. Madison: Research Publishers; 2006.

44. IBM Corporation. IBM SPSS Statistics for Windows, Version 25.0. Armonk, NY: IBM Corporation; 2017.
45. Nooteboom LA, Kuiper CHZ, Mulder EA, Roetman PJ, Eilander $\mathrm{J}$, Vermeiren R. What do parents expect in the 21 st century? A qualitative analysis of integrated youth care. Int J Integr Care. 2020;20(3):8. https://doi.org/10.5334/ijic.5419.

46. Reardon T, Harvey K, Baranowska M, O’Brien D, Smith L, Creswell C. What do parents perceive are the barriers and facilitators to accessing psychological treatment for mental health problems in children and adolescents? A systematic review of qualitative and quantitative studies. Eur Child Adolesc Psychiatry. 2017;26(6):623-47. https://doi.org/10.1007/s00787-016-0930-6.

47. Coyne I, McNamara N, Healy M, Gower C, Sarkar M, McNicholas F. Adolescents' and parents' views of Child and Adolescent Mental Health Services (CAMHS) in Ireland. J Psychiatr Ment Health Nurs. 2015;22(8):561-9. https://doi.org/10.1111/jpm. 12215.

48. Oruche UM, Downs S, Holloway E, Draucker C, Aalsma M. Barriers and facilitators to treatment participation by adolescents in a community mental health clinic. J Psychiatr Ment Health Nurs. 2014;21(3):241-8. https://doi.org/10.1111/jpm.12076.

49. Hackett CL, Mulvale G, Miatello A. Co-designing for quality: creating a user-driven tool to improve quality in youth mental health services. Health Expect. 2018;21(6):1013-23. https://doi. org/10.1111/hex.12694.

50. Courey L, Hyndman D, Sheasgreen C, McCay E. What we know-and want to know-about Family Connections: a review from the perspective of lived experience. Curr Opin Psychol. 2021;37:44-8. https://doi.org/10.1016/j.copsyc.2020.07.029.

51. Muir K, Powell A, McDermott S. 'They don't treat you like a virus': youth-friendly lessons from the Australian National Youth Mental Health Foundation. Health Soc Care Community. 2012;20(2):181-9. https://doi.org/10.1111/j.1365-2524.2011. 01029.x.

52. Levasseur MA, Roeszler L, den Besten L, Pinkoski K. Invited commentary: ACCESS Open Minds family and carers council. Early Interv Psychiatry. 2019;13(Suppl 1):68-70. https://doi.org/ 10.1111/eip.12821.

53. Reaume-Zimmer P, Chandrasena R, Malla A, Joober R, Boksa $\mathrm{P}$, Shah JL, et al. Transforming youth mental health care in a semi-urban and rural region of Canada: a service description of ACCESS Open Minds Chatham-Kent. Early Interv Psychiatry. 2019;13(Suppl 1):48-55. https://doi.org/10.1111/eip.12818. 